\title{
Transexualidad y transgenerismo. Una aproximación teórica y etnográfica a dos paradigmas enfrentados
}

\author{
Transsexuality and Transgenderism. \\ A Theoretical and Ethnographical Approach \\ to Two Conflicting Paradigms
}

Jordi Mas Grau

Universitat de Barcelona

\section{RESUMEN}

En este artículo analizamos los dos grandes paradigmas desde los que se ha conceptuado el fenómeno trans en las sociedades occidentales: la transexualidad y el transgenerismo. Basándonos en los datos obtenidos de dos investigaciones cualitativas realizadas en Cataluña (España), mostraremos la existencia de conflictos entre personas y grupos cercanos a uno y otro paradigma. Algunas personas que se sitúan en la órbita de la transexualidad critican a aquellas cuyos cuerpos y subjetividades no se ajustan a la lógica binaria porque consideran que comprometen su proyecto de integración social, mientras que algunas activistas transgeneristas lamentan que desde ciertos sectores se reniegue de lo trans y se busque la normalización social. El artículo concluye con una problematización sobre la capacidad de las personas trans para reforzar o subvertir el sistema de sexo/género.

Palabras clave: Transexualidad; Transgenerismo; Sexo; Género; Biomedicina.

\section{SUMMARY}

This paper analyses the two major paradigms through which the trans phenomenon has been conceptualized in Western societies: transsexuality and transgenderism. Based on data obtained from two qualitative research projects conducted in Catalonia (Spain), we show the existence of conflicts between individuals and groups close to both paradigms. Some who consider themselves to fall within the realm of transsexuality criticize those whose bodies and subjectivities do not conform to gender binary believing them to compromise their social integration project. On the other hand, some transgenderist activists complain that certain sectors rejecting their trans condition, seeking social normalization. The paper concludes with a problematization of trans people's ability to reinforce or subvert the sex/gender system.

Key words: Transsexuality; Transgenderism; Sex; Gender; Biomedicine. 


\section{INTRODUCCIÓN}

Concebir el género como la prolongación natural del dimorfismo sexual ${ }^{1}$ constituye uno de los postulados centrales del sistema de sexo/género ${ }^{2}$ de las sociedades occidentales. El quebrantamiento de dicho postulado, esto es, el deseo de expresar un género distinto a aquel que se asigna en función de la morfología corporal, es un fenómeno que puede ser entendido recurriendo a uno de los dos paradigmas existentes: la transexualidad y el transgenerismo. Como veremos a continuación, la transexualidad es un concepto etic, creado por la biomedicina, con el que se legitima el empleo de herramientas diagnósticas y tecnologías hormono-quirúrgicas sobre aquellas personas que rechazan el género de asignación. El proceso medicalizador tiene como objetivo la corrección de lo que se concibe como una discordancia entre la identidad de género y el cuerpo de la persona, para que ésta pueda encarnar a uno de los dos géneros socialmente disponibles. Por el contrario, el transgenerismo es un concepto emic desarrollado por las propias personas trans para desvincularse de la gestión biomédica de sus cuerpos y subjetividades. Desde el transgenerismo se exploran formas de experiencia y visibilidad que trascienden los dualismos y se problematizan las categorías que conforman nuestro universo sexogenérico.

En el presente artículo analizaremos los principios constitutivos de ambos paradigmas, sus limitaciones y potencialidades, así como su capacidad para reforzar o subvertir el sistema de sexo/género. Veremos modos distintos de concebir el cuerpo y la identidad de género, distintas formas de posicionarse ante los códigos sexogenéricos. Asimismo, prestaremos atención a los debates y conflictos existentes entre personas y grupos cercanos a uno y otro paradigma. Todas estas cuestiones serán abordadas dando una especial relevancia a los discursos generados por las propias personas trans ${ }^{3}$. Es importante destacar que la transexualidad y el transgenerismo son aquí concebidos como tipos ideales, es decir, como la abstracción ideal de aquello que en la realidad acontece como mera tendencia. Estos tipos ideales constituyen un instrumento de análisis para ordenar experiencias y prácticas que son diversas y complejas. En consecuencia, será difícil encontrar a una persona que se ajuste estrictamente a los parámetros que conforman un paradigma. Lo más común es que sus vidas se sitúen en algún lugar comprendido entre los dos polos, pudiendo moverse entre ellos en función de múltiples factores.

Los datos para la elaboración de este texto proceden de dos investigaciones realizadas en Cataluña (España). Por un lado, mi investigación doctoral sobre la patologiza-

\footnotetext{
${ }^{1}$ La noción del dimorfismo sexual en tanto que realidad meramente natural ha sido problematizada desde la historia (cf. Laqueur 1994), los estudios intersex (cf. Cabral 2009) y hasta por algunos biólogos que destacan el carácter socio-biológico del cuerpo sexuado (cf. Fausto-Sterling 2006).

${ }^{2}$ Empleamos este concepto en un sentido similar al que le dio Gayle Rubin. Para esta pionera del construccionismo social, dicho sistema es el "conjunto de disposiciones por el que una sociedad transforma la sexualidad biológica en productos de actividad humana, y en el cual se satisfacen estas necesidades humanas transformadas" (Rubin 1986: 97).

3 A lo largo del texto utilizaremos el prefijo "trans" como una categoría paraguas con la que referirnos de forma conjunta a todas aquellas personas que expresan/experimentan un género distinto al asignado.
} 
ción y medicalización de las personas trans (Mas Grau 2014). Por el otro, una investigación que tenía por objeto analizar los discursos, representaciones y prácticas de las mujeres trans a lo largo de su proceso de feminización ${ }^{4}$. La principal técnica empleada en ambas investigaciones fueron las entrevistas en profundidad semi-dirigidas a personas trans (en total, 13 entrevistas a hombres trans y 41 a mujeres) y profesionales que trabajan con esta población (10 entrevistas). También se recurrió a la observación participante en eventos organizados por - y/o dirigidos a- estas personas, la observación de uno de los principales foros virtuales en lengua castellana (el Diario Digital Transexual) y un grupo de discusión con siete mujeres trans.

\section{EL PARADIGMA DE LA TRANSEXUALIDAD: LO TRANS COMO UN RITO DE PASO}

Como apunta Hausman (1995; 1998), la aparición del concepto de «identidad de género" y el desarrollo de la endocrinología y la cirugía plástica proporcionan las bases tecnológicas e ideológicas para el surgimiento de la transexualidad. Es el endocrinólogo Harry Benjamin quien a mediados de los años 60 del siglo XX populariza este término para referirse al "deseo irreversible de pertenecer al sexo contrario al genéticamente establecido y de asumir el correspondiente rol, además de solicitar un tratamiento hormonal y quirúrgico para corregir la discordancia entre la mente y el cuerpo" (Benjamin 1966: 30). El trabajo de Benjamin y el de otros coetáneos suyos como Money y Ehrhardt (1982), Stoller (1968; 1975) o Fisk (1974) será determinante para la configuración del actual paradigma biomédico de la transexualidad, pues establecen los primeros protocolos para la denominada "terapia de reasignación sexual". Con anterioridad a Benjamin, el tratamiento hormono-quirúrgico no era unánimemente aceptado por los profesionales, los cuales se decantaban mayoritariamente por una atención psicoterapéutica destinada a corregir los deseos transexualizadores de la persona trans (Billings y Urban 1998; Nieto 2008).

La biomedicina considera que la transexualidad es fruto de una alteración, producida durante el desarrollo intrauterino, que provoca que el cerebro se desarrolle en sentido inverso al sexo cromosómico, gonadal y genital (Zhou et al. 1995; Kruijver et al. 2000; Gómez-Gil, Esteva de Antonio y Fernández-Tresguerres 2006). Aunque el tratamiento privilegiado se basa en la modificación corporal del sujeto y no en la psicoterapia reconstructiva, la transexualidad está catalogada como un trastorno mental en los dos principales manuales clasificatorios: el DSM de la Asociación Psiquiátrica Americana y la CIE de la Organización Mundial de la Salud. Este es un hecho ciertamente paradójico, pues se accede a los deseos de transformación corporal de unas personas que, supuestamente, padecen un trastorno mental (Mas Grau 2013; Mas Grau y Guasch 2013).

La adscripción al paradigma de la "transexualidad" supone para muchas personas trans la adopción del relato biomédico en torno a las causas generadoras del fenómeno, y la visión de su propia condición como una anomalía. Como sostiene Coll-

\footnotetext{
4 "Representaciones y prácticas en el proceso de feminización de mujeres transexuales" (financiada por el Instituto de la Mujer-Ministerio de Sanidad, Servicios Sociales e Igualdad. 2012-2013. Ref. 2011-0004-INV-00124).
} 
Planas (2010a: 57), «las personas trans acuden a ellos (los profesionales médicos) tras interiorizar que su falta de correspondencia sexo/género es anormal, patológica, algo que los profesionales generalmente refuerzan". La reproducción del discurso "enfermizante" de la biomedicina se observa en las respuestas de algunas de las personas trans entrevistadas a la pregunta sobre cuáles eran, en su opinión, las causas de la transexualidad: "Simplemente, igual que hay personas que nacen con problemas físicos, que les falta un brazo o una pierna, nosotras nacemos con un sexo mal puesto" (Bego) $)^{5}$

Pero la reproducción, más o menos fiel, del discurso médico por parte de la persona transexual no solo puede interpretarse como la interiorización de un discurso hegemónico, en una muestra de esa "violencia simbólica" de la que nos hablaba Bourdieu (2003). La aceptación de las tesis biologistas podría también entenderse como una estrategia personal para combatir la visión, todavía existente, de la transexualidad como una aberración y del transexual como un pervertido. Defender una explicación congénita tiene un efecto desculpabilizador porque supone enfatizar los designios de la naturaleza en detrimento de la voluntad del sujeto, y permite recubrir la transexualidad con un halo de cientificidad que dificulta la condena moral y, de paso, justifica el acceso al tratamiento.

Por otra parte, la antropología nos ofrece una herramienta conceptual idónea para entender el modo en que la clase médica y algunas personas trans conciben la transexualidad: los ritos de paso. Para van Gennep (1986), el rito de paso cumple la función social de escenificar simbólicamente la transición entre dos estados fijos, estables y culturalmente reconocidos. De este modo, la transexualidad o, mejor dicho, el proceso transexualizador puede ser entendido como un rito de paso mediante el cual la persona pasa de un lugar a otro en el sistema binario de género. El objetivo de las personas que comparten esta visión es lograr la aceptación social representando la normalidad genérica:

Mi meta es llegar a ser una mujer normal y que la sociedad me acepte (...) Transexual lo eres porque estás pasando por una transición de hombre a mujer. Entonces eres transexual durante el cambio. Cuando has reasignado tu sexo, ya eres mujer (Andrea).

Van Gennep divide los ritos de paso en tres fases: los ritos de separación (preliminares), de margen (liminares) y de agregación (postliminares). Con los ritos de separación el individuo se aleja del viejo mundo, de su anterior posición o estatus; los de transición son los ritos efectuados cuando el individuo se encuentra en el margen, entre dos mundos, y ayudan a prepararse para la posterior reincorporación a la estructura social; finalmente, los ritos de agregación sancionan la integración al nuevo mundo, la obtención de un nuevo estatus.

En el caso de las personas trans, no existe un "rito de separación" generalizado y claramente delimitado. El recurso al travestismo esporádico en espacios seguros (a salvo de la mirada reprobatoria del entorno) cuando todavía no se ha producido la "Salida del armario" podría entenderse como una primera tentativa de separarse del género de asignación. En otras ocasiones, la huída del hogar familiar para iniciar la (re)cons-

\footnotetext{
${ }^{5}$ Con el fin de preservar el anonimato de las personas entrevistadas empleamos nombres ficticios, pero siempre respetando el género de los originales.
} 
trucción corporal constituye la escenificación ritual del abandono del viejo mundo. Y en el caso de aquellas personas que acuden a una Unidad de Trastornos de la Identidad de Género (UTIG) ${ }^{6}$, el proceso diagnóstico que han de seguir obligatoriamente para demostrar que pertenecen al género que dicen experimentar, es el rito preliminar que da acceso al tratamiento financiado por la sanidad pública española. La obtención del diagnóstico psiquiátrico legitima la desvinculación con el género de asignación y, como sugiere Hérault (2005: 173), permite — temporalmente- yuxtaponer a la identidad experimentada por el sujeto una nueva identidad patologizada y medicalizada: "soy transexual", es decir, "una mujer/un hombre con un cuerpo equivocado".

El proceso de (re)construcción corporal coincide plenamente con el concepto de "rito de margen" o "liminar". Una vez han decidido abandonar su género de asignación, las personas efectúan una serie de cambios corporales a modo de preparación para la obtención de un nuevo estatus. Es ésta la etapa más esperada y a la vez temida por muchas personas trans. Siguiendo el trabajo de van Gennep, Victor Turner (2008) recuerda que los individuos liminares se encuentran en una posición interestructural, son seres ambiguos y paradójicos que confunden las categorías habituales (en este caso, las categorías de género). Mary Douglas (2007) añade que, en tanto que inclasificables, pues no son ni una cosa ni la otra o, tal vez, ambas cosas al mismo tiempo, los seres transicionales son considerados como particularmente peligrosos, contaminantes, por lo que son objeto de una atención especial (de ahí la supervisión médica del proceso de transformación corporal). No hay mejores conceptos que los de "liminaridad" y "contaminación" para entender la zozobra social causada al observar el aspecto andrógino de aquellas personas que se encuentran en las primeras fases del proceso transexualizador:

Estoy intentando aparentar un género para que mi entorno me trate como yo me siento. Pero es innegable que tengo un cuerpo de hombre y eso lo ve todo el mundo. Soy consciente de que mi aspecto provoca dolor de ojos (Sara).

Anne Bolin (1988) analiza la transexualidad apoyándose en la teoría de los ritos de paso y el interaccionismo simbólico. En su estudio, la autora recuerda que la identidad personal está estrechamente relacionada con la identidad social, puesto que la autopercepción está en parte determinada por la mirada de los otros: "En cierta medida, nos vemos a nosotros mismos tal y como los otros nos ven" (Bolin 1988: 70). Es por ello que, por mucho que las personas cercanas a la transexualidad compartan con la clase médica una noción esencial y congénita de la identidad (afirman haber sentido desde siempre que pertenecen al género que desean representar), entienden que su identidad no podrá consolidarse hasta que no obtengan el reconocimiento de los demás. Y esto se consigue con una corporeización adecuada del género:

Hoy en día me defino como una mujer porque yo me siento mujer. Pero realmente yo sé que mi aspecto no es de mujer, es intermedio, es de un chico femenino vestido de

\footnotetext{
${ }^{6}$ Las UTIG son unidades hospitalarias creadas en aquellas Comunidades Autónomas españolas que han decidido financiar y supervisar el tratamiento hormonoquirúrgico. Para poder acceder al tratamiento, la persona debe antes obtener un diagnóstico psiquiátrico que acredite su transexualidad. Para un análisis del proceso diagnóstico realizado en una UTIG española, cf. Mas Grau (2013).
} 
mujer. Yo no me siento así, pero la gente realmente me ve así, y eso lo notas cuando te miran de forma rara (Andrea).

Desde sus inicios, la clase médica ha presentado las cirugías de reasignación genital como la última fase del proceso transexualizador. Las popularmente conocidas como "operaciones de cambio de sexo" han sido concebidas como el "ritual de agregación" necesario para adquirir legítimamente un nuevo estatus de género. La puerta del quirófano es el umbral simbólico cuyo traspaso conlleva la incorporación a un nuevo mundo: "Creo que el transexual lo es durante las dos horas y media de mi operación. Ya está. A partir de ahí, deja de serlo. Ni lo fue, y ya no lo es" (cirujano de una clínica privada). Es más, algunos médicos han presentado estas cirugías como algo más que una simple técnica quirúrgica con la que se obtiene una nueva morfología genital. Y es que la operación ha sido también publicitada como una suerte de llave maestra para experimentar plenamente el género deseado y obtener una posición de normalidad en la estructura de género. Esta visión idealizada también la comparten algunas de las personas entrevistadas: "Queremos un coño porque queremos sentirnos mujer al 100\%, ser una mujer más, tener lo que tienen ellas y hacer una vida normal" (Jessica). Con todo, para convertirse en un hombre o una mujer de pleno derecho todavía falta un último "rito postliminar", a saber, el cambio de sexo y de nombre en todos los documentos y registros oficiales ${ }^{7}$. A este respecto, Carlos tiene bien claro cuándo empieza y acaba el rito de paso transexual:

La transexualidad es el proceso que haces de cambio. Desde que empiezas, con el hormonarte o la primera operación, hasta que ya te dan tu DNI con tu nombre y tu sexo cambiado. Es el proceso, simplemente el proceso. No es serlo para toda la vida porque solo hay hombres y mujeres, no hay hombres intermedios.

Como vemos, tanto para la clase médica como para muchas de estas personas, la transexualidad no es un fin en sí mismo, sino un proceso medicalizado para pasar de un género a otro. Esta visión procesual se refleja en los términos empleados para referirse a aquellos que están siguiendo la terapia de modificación corporal: para un profesional de una UTIG, "Son personas en transición"; mientras que Nuria afirma que "actualmente estoy transicionando". No se contempla la posibilidad de ocupar un espacio de género intersticial:

A mí eso de "en tierra de nadie" no me gusta. A ver, hay dos géneros, y yo en medio no voy a estar. Voy a estar en el lado de la mujer, o en el otro. Aunque haya un periodo de tiempo que, por "X" razones, tengas que estar en medio. No voy a estar en medio siempre, a mí no me gusta eso (Toni).

El paso por un proceso liminar modifica la más íntima naturaleza del sujeto, ya que "no se trata de una mera adquisición de conocimientos, sino de un cambio ontológico" (Turner 2008: 113). Es por ello que la metáfora del renacimiento acos-

${ }^{7}$ En España, los requisitos para solicitar el cambio de sexo registral están establecidos en la Ley 3/2007, de 15 de marzo, reguladora de la rectificación registral de la mención relativa al sexo de las personas. Con la nueva ley se excluye la obligatoriedad de someterse a las cirugías de reasignación sexual, pero es necesario que la persona presente un diagnóstico psiquiátrico y siga una terapia hormonal durante un periodo mínimo de dos años. 
tumbra a ser recurrente cuando se aborda la finalización del rito de paso. En unas jornadas organizadas por una asociación LGTB catalana, la madre de un chico trans explicaba cómo afrontaba la transformación de su hijo: "Has de hacer un duelo para superar la angustia de cerrar un episodio. Un duelo para despedirte de Clara y poder dar la bienvenida a Andrés. Es como si me hubiera nacido un nuevo hijo". Para no pocas personas trans, este cambio ontológico ha de implicar un cambio en el modo de referirse a ellas. La identidad transexual es una identidad temporal y liminar, una identidad que la persona adopta en un momento de cambios para luego abandonarla (Bolin 1988). Estas personas tan solo aceptan que se las denomine "transexuales" mientras se encuentran inmersas en el proceso de transformación corporal. Tras la finalización del mismo habrán adquirido un nuevo estatus:

No me molesta que me llamen transexual porque actualmente soy una transexual, estoy cambiando mi cuerpo. Pero después de operarme sí que me molestará porque seré una mujer y tendré un coño y unos pechos como cualquier mujer (Jessica).

En su estudio sobre el estigma, Goffman (2006) distingue entre sujetos "desacreditados" y "desacreditables". Los primeros han de enfrentarse al oprobio y al rechazo social por presentar un atributo negativo que es conocido por los demás, mientras que los segundos han de manejar cuidadosamente la información que transmiten en la interacción social si quieren seguir ocultando un estigma que, de hacerse visible, los convertiría de inmediato en sujetos desacreditados. Mientras que el desacreditado debe manejar tensiones, el desacreditable debe manejar informaciones. Siguiendo esta tipología, podemos afirmar que las personas transexuales que aspiran a pasar por un hombre o una mujer "normales y naturales" tratan por todos los medios de evitar ser desacreditadas. Para proyectar una imagen de género adecuada, deben llevar a cabo un correcto "manejo de las impresiones" (Garfinkel 2006), es decir, una tarea constante de vigilancia, planificación y gestión de su puesta en escena. Con este fin, estas personas no solo recurren a las hormonas y a las cirugías, ya que ponen en práctica una amplia gama de estrategias corporales: modifican su vestimenta, utilizan cosméticos, modulan el tono de voz, moldean su cuerpo en un gimnasio y con dietas, vigilan su lenguaje corporal y su expresividad, etc.

Estas estrategias no son exclusivas de las personas trans. Una de las mayores contribuciones de los estudios etnometodológicos de Garfinkel (2006) y Kessler y McKenna (1985) consistió en pensar que la cotidianidad de estas personas no constituía un caso excepcional, sino un caso paradigmático que permitía apreciar con mayor claridad las estrategias que todos nosotros ponemos en marcha para lograr una identidad reconocible. En el caso de las personas trans, la gestión de las apariencias ha de ser mucho más acurada porque están representando un género que socialmente no les corresponde. Es precisamente este mayor esmero en presentarse adecuadamente ante los demás, lo que hace que estas personas conozcan a la perfección los entresijos de una puesta en escena que la mayoría efectuamos rutinaria e irreflexivamente.

Con todo, estas personas han de ser conscientes de que, si bien las tecnologías corporales disponibles permiten la obtención de una apariencia cercana a los estándares normativos, siempre serán sujetos desacreditables porque nunca podrán borrar totalmente las huellas que delatan que están representando un género distinto al de asignación. Siempre existirán pruebas delatoras de carácter biográfico (como una foto- 
grafía de la infancia), morfológico (la nuez de Adán, las manos o la estructura ósea, en el caso de las mujeres trans) o biológico (las gónadas o los cromosomas). En consecuencia, la creencia — difundida por el estamento médico y compartida por algunas personas trans- de que el tratamiento hormonoquirúrgico garantiza la entrada al reino de la normalidad genérica, contiene una fuerte carga nociva. El siguiente testimonio extraído de un foro de internet, contundente y desgarrador, muestra a la perfección el profundo desánimo que puede embargar a aquella persona que desea con todas sus fuerzas invisibilizar su paso por un proceso transexualizador y acaba siendo "descubierta":

\begin{abstract}
Me siento un monstruo (...) Siento que todo lo que me he esforzado en conseguir mi sueño ha sido en vano. Siempre se me notará que soy un travelo, un monstruo, un engendro que la gente mirará mal. He luchado con lágrimas, sudor y sangre, simplemente para verme como yo misma, pero veo que ese sueño nunca llegará a cumplirse, y que solo será una cruel pesadilla de lágrimas envueltas en tristeza y odio hacia mí misma, hacia este mundo y hacia todo. Sólo quiero ser una chica NORMAL, nada más, ni destacar, ni estar por debajo. Pero no sé qué más hacer para conseguirlo, he agotado todas mis fuerzas. Y ahora solo un pensamiento pasa sobre mi cabeza: la idea de caer en un profundo sueño y no despertar nunca más. Hoy me han dicho unas palabras que me han dolido mucho, tales como mi altura inusual, mi nuez de Adán, mis facciones angulosas y mi poco pecho. No es tan complicado llegar a la conclusión de que soy lo que soy: un monstruo incapaz de cortar todo de raíz.
\end{abstract}

\title{
EL PARADIGMA DEL TRANSGENERISMO: LO TRANS COMO UN FIN EN SÍ MISMO
}

Tras haber sido largo tiempo objeto de estudio de un amplio elenco de expertos, las personas categorizadas como "transexuales" o "travestidos" piden la palabra a finales de los años 70 del siglo XX para que su voz sea escuchada más allá de la consulta o el diván. Estas personas harán uso de su experiencia vital, política e intelectual para generar un conocimiento socialmente relevante y reivindicar otras formas de pensar su existencia que a menudo chocarán con los saberes existentes. Desde el derecho a la autorreferencialidad, empezarán a proliferar estudios académicos y encendidos panfletos políticos, de los que surgirán nuevos conceptos, significados y luchas.

La acuñación del término "transgenerista" se la debemos a Virgina (antes Charles) Prince. Esta doctora en farmacología decide vestir como mujer a tiempo completo y tomar hormonas feminizantes pero, contrariamente a lo establecido por el saber médico de la época, quiere conservar sus genitales masculinos. El hecho de no sentirse identificada con los conceptos "travestido" y "transexual" le lleva a crear dos nuevos términos que trastocarán profundamente el conocimiento y las experiencias trans: "He acuñado las palabras "transgenerismo" y "transgenerista" para describir a la gente, como yo misma, que tiene pechos y vive a tiempo completo como mujer sin tener intención alguna de someterse a la cirugía genital" (Prince 1997: 469). Si Virginia Prince crea la palabra "transgenerista", es Leslie Feinberg quien le confiere su actual significado en un panfleto de 1992. Para Feinberg resulta necesario establecer una alianza política que incluya a todas aquellas personas oprimidas y marginadas por no ajustarse a las normas de género, tales como travestidos, transexuales, drag queens, drag 
kings, andróginos, hombres afeminados, butch, etc.: "Muchas de estas palabras no las hemos escogido. No todos nos sentimos incluidos en ellas. Es difícil combatir una opresión sin un nombre que connote orgullo, sin un lenguaje que nos honre" (Feinberg 2006: 206). Y es justamente el vocablo "transgenerista" — o "transgénero"— el paraguas y símbolo de orgullo de este movimiento pangenérico. En adelante, las personas trans tomarán parte activa en ese "campo académico interdisciplinar y socialmente comprometido" (Stryker 2006: 3) de los estudios trans - o transgender studies(Cf. Stryker y Whittle 2006; Missé y Coll-Planas 2010; Stryker y Aizura 2013).

Si en el paradigma de la transexualidad lo trans es visto como un proceso para llegar a un fin — representar la normalidad genérica-, para el transgenerismo es un fin en sí mismo, un espacio vagamente delimitado desde el que cuestionar la naturalización y genitalización del género. El transgenerismo abraza a una multiplicidad de subjetividades y cuerpos que se decantan por la mezcla de caracteres sexogenéricos. Son personas que pueden recurrir a las hormonas y a determinadas cirugías, pero que conservan deliberadamente sus genitales y algunos de sus caracteres sexuales secundarios. Lo trans es aquí entendido como un rechazo de la lógica binaria:

No me gusta para nada definirme, pero si me lo preguntas te diré que me defino como una mujer entre comillas (...) E íntimamente, sexualmente, me considero un híbrido. Tengo una identidad femenina y un cuerpo que mezcla las dos cosas: híbrido, mujer con pene, llámalo como quieras (Mónica).

Desde el paradigma de la transexualidad se concibe la identidad de género como algo ya establecido definitivamente en el momento de nacer. La persona cercana a este paradigma no cuestiona su identidad, sino su cuerpo, que es visto como el elemento erróneo que hay que reajustar —o reasignar- con tecnologías médicas. Por el contrario, desde el transgenerismo se considera que tanto el cuerpo como la identidad son constructos sociales, por lo que ambos son susceptibles de (re)construirse constantemente. Desde este paradigma no se persigue una identidad estable ni un cuerpo estandarizado, sino la labilidad identitaria y corporal. El reconocimiento del carácter biográfico y contextual de la identidad de género lleva al transgenerismo a problematizar las categorías identitarias hegemónicas, desvelando su poder normalizador y constringente. Ahora bien, este paradigma ha de hacer frente a la eterna ambivalencia de las identidades: limitan nuestro campo experiencial, pero nos ofrecen estabilidad. Y cuando se refieren a un sujeto colectivo, hacen posible la lucha política y la reivindicación de derechos. El transgenerismo puede deconstruir las identidades existentes e incluso declararse postidentitario, pero no puede olvidar que, a veces, es necesaria cierta configuración identitaria para la solidaridad endogrupal y la visibilidad social:

Entonces, lo trans es como un movimiento identitario muy necesario para la reivindicación de derechos en un contexto en el que, desde otros ámbitos, como el teórico o el artístico, estamos empezando a barajar teorías postidentitarias (...) Pues aquí se ha juntado un buen pitote. Supongo que este pitote, que es una opresión sobre nosotros, hace que entre las personas trans haya conflictos, porque algunas pues tenemos una manera de pensar más hiperidentitaria, otra gente tiene una manera de pensar más postidentitaria, $\mathrm{y}$ entonces pues hemos entrado un poco en conflicto (Pere).

El género conforma un sistema normativo con sanciones previstas para todo aquel que no se ajusta a lo establecido. Las personas trans saben mejor que nadie que vul- 
nerar los códigos sexogenéricos tiene un coste y que se necesitan herramientas para poder afrontarlo. Cati explica que la experiencia vital y la confianza en una misma son muy importantes para decidir enfrentarse a determinadas situaciones, como salir de casa sin maquillar y con una barba incipiente. Otras personas opinan que, a parte de estos recursos personales, es fundamental contar con una red social de seguridad, como la que ofrecen las asociaciones:

Y claro, igual me permiten (las asociaciones trans) enfrentarme de otra manera, es decir, igual esa fuerza colectiva hace que sienta una seguridad de poder enfrentarme y poder tomar una actitud desafiante, pero a la vez positiva (Pere).

A pesar de contar con recursos personales y sociales, algunas de estas personas reconocen las dificultades para conciliar una ideología de género subversiva con la vida cotidiana. Si los más cercanos al paradigma de la transexualidad tienen como reto principal lograr la invisibilidad social, esto es, borrar su paso por un proceso transexualizador y pasar por alguien "normal", aquellas personas que entrarían en la órbita transgenerista se enfrentan justamente al problema contrario: ser visibles socialmente. El género es un entramado de códigos que "establecen el campo ontológico en el que se puede atribuir a los cuerpos expresión legítima" (Butler 2007: 29). Es decir, las personas devienen inteligibles si se ajustan a una de las dos categorías de género disponibles. Aquellas que encarnan la ambigüedad e introducen la discontinuidad en la tríada "morfología corporal/ identidad de género/orientación sexual", caen en el terreno de lo abyecto y se deshumanizan.

Las personas transgeneristas luchan para lograr otras formas de pensar el género, y para ello están dispuestas a exponer sus cuerpos en el campo de batalla. Sin embargo, la lucha desgasta y tiene sus límites. Todos sentimos la necesidad de ser inteligibles en la interacción social, de lograr cierto reconocimiento por parte de nuestros interlocutores, y estas personas no son una excepción. En consecuencia, algunas personas próximas al transgenerismo admiten que resulta extremadamente complicado y costoso subvertir el género constantemente, por lo que, a veces, han de tomar ciertas decisiones a pesar de sus convicciones ideológicas:

Yo tomo hormonas pero me gustaría no tener que tomarlas, me gustaría no tener que estar pendiente de las hormonas, y a veces las he dejado pero, pero he vuelto porque me cuesta vivir sin las hormonas. Me ralla que la gente pueda dudar de si soy una chica. Y todo mi esquema teórico: "Qué más da, en el fondo no somos ni hombres ni mujeres, teoría queer", ¿de qué me ha servido? Para nada, no te sirve para nada la teoría queer. O sea, tú cuando vas por la calle y te tratan en femenino pillas una rallada del mil. No dices: total, es una construcción social, no. Y es una putada, porque quieres escapar de esto pero no puedes (Hombre trans; en Coll-Planas 2010b: 217).

\section{"EL INFIERNO SON LOS OTROS",}

La mayoría de las personas trans saben, aunque no dominen la terminología, que existen otras personas que toman un camino diferente al suyo, y a veces significan

\footnotetext{
${ }^{8}$ Para el título de este apartado hemos tomado prestada la famosa y controvertida frase que Sartre formula en A puerta cerrada (Huis Clos).
} 
esta diferencia en términos de un Otro ontológico. La sensación de otredad se manifiesta cuando las asociaciones reivindican derechos distintos y hasta contradictorios, se producen enfrentamientos verbales en espacios de debate o cuando una figura trans adquiere notoriedad y no se la reconoce como a un igual. La visión de ese Otro puede basarse en el respeto, la indiferencia, la desconfianza o la abierta hostilidad. A lo largo del trabajo de campo realizado en Cataluña se ha constatado la existencia de un amplio abanico de posicionamientos, pero es de destacar el fuerte recelo y la animadversión que sienten algunos hacia aquellos con un proyecto vital bastante alejado del suyo. Como veremos acto seguido, la censura del Otro podemos encontrarla en gentes cercanas a uno y otro paradigma, pero se manifiesta en mayor medida entre aquellas que aspiran a la normalidad sexogenérica.

El recelo que siente la persona transexual hacia la transgenerista es muy similar al que ha sentido el gay hacia el marica. Guasch (2005; 2013) y Mira (2004) explican que, durante la Transición española, los homosexuales buscaron la integración social tratando de ofrecer una imagen respetable. En este proyecto de normalización no tenían cabida aquellas figuras cuya imagen se consideraba indeseable, como la "loca" (el extrovertido afeminado) o el "degenerado" (el Genet que hacía gala de una vida promiscua y viciada), por lo que fueron apartadas por los propios miembros del colectivo. Se produce entonces la distinción entre dos tipos de homosexuales, "uno de los cuales merece siempre la comprensión, tolerancia o incluso admiración y el otro o no interesa o es simplemente un vicioso que produce repugnancia" (Mira 2004: 213). Si el marica pasa por un proceso ascendente de movilidad social y se convierte en gay (Guasch 2005), podría decirse que el travestí del Tardofranquismo y la Transición ha empezado a ser reconocido socialmente cuando se ha convertido en transexual medicalizado. En su lucha por lograr la integración y los derechos civiles, algunas personas transexuales condenan a todo aquel que no contribuye a la elaboración de una imagen colectiva caracterizada por la moderación y la discreción: "Salen cuatro petardas en televisión diciendo: "Tengo polla y estoy genial", y eso crea que las demás personas tengan un rechazo porque nadie quiere para sus hijos algo asín (Vanessa).

Las ciencias sociales han mostrado que la configuración de un Otro es un componente determinante para la formación de una identidad grupal. Si, como afirma Norbert Elias (1990), no puede existir una identidad del Yo sin una identidad del Nosotros, no es menos cierto que "sin "los otros" no hay necesidad de definirnos a nosotros mismos" (Hobsbawm 1994: 9). La creación de una figura antitética ayuda a clarificar los límites de un Nosotros, puesto que es tan importante definir qué es lo que somos (semejanza) como determinar aquello que no podemos ser (diferencia). Hay que trazar barreras físicas y/o simbólicas para poder enaltecer lo propio frente a lo extraño. Hay que configurar ese "exterior constitutivo" (Derrida 1972), una otredad que es fundamento y requisito para la consolidación de la propia identidad. El salvaje, la puta, el marica, el negro o el inmigrante han sido las grandes figuras de la otredad que han ayudado a trazar las fronteras en Occidente. En el caso que nos ocupa, el transgénero es el reverso negativo de un transexual que se preocupa en todo momento de diferenciar ambos fenómenos en su lucha por la aceptación:

Es muy respetable (el transgenerismo). Que hagan lo que quieran, que fluctúen (...) En lo único que nos repercute a nosotros es que entonces la sociedad no nos entiende, porque 
lo que no se puede hacer es hormonarte, tener barba, tener voz de hombre y tener tetas (...) Pero cada uno puede ser como quiera siempre y cuando no nos perjudiquen, porque bastante nos está costando presentarlo a la sociedad como una cosa normal y corriente como para que encima nos incluyan dentro del mismo grupo (...) Lo que digo es que no tendrían que entrar en la misma palabra, tendrían que ser dos cosas diferentes, se tendría que diferenciar desde el principio para que la sociedad sepa que nuestra definición es finalizar en hombre o mujer, y su definición es ser andrógino, ambivalente (Carlos).

Algunas de las personas que se desmarcan rotundamente del transgenerismo y que critican su puesta en escena justifican su posicionamiento por la precaria situación que está atravesando la asistencia pública a la transexualidad en España. Recuerdan que la decisión de financiar el tratamiento transexualizador, por parte de algunas Comunidades Autónomas españolas, se fundamentó en gran medida en el carácter no electivo de dicho tratamiento. Por tanto, estas personas consideran que si a unas políticas de importantes recortes del gasto público, le añadimos el hecho de que algunos/as trans manifiestan que es posible desarrollarse como personas sin necesidad de recurrir a tratamientos hormonoquirúrgicos, todo ello pone en peligro la cobertura pública del proceso terapéutico. La relación entre la transexualidad y el transgenerismo es así entendida como si fuera un "juego de suma cero":

Que a mí me digan que una persona no se tiene por qué operar, que puede vivir perfectamente con pelo en el pecho, yendo a la playa quitándose la camiseta y con dos pechos colgando. Pues no, porque luego pasa lo que pasa, que la gente se agarra a lo que sea: "Pues entonces quitamos las operaciones por la Seguridad Social porque no lo necesitáis, no es importante» (...) O lo del tema de la hormonación, que no hace falta hormonarse. "iNo hace falta hormonarse? Pues como no hace falta, quitamos la hormonación" (Darío).

Por su parte, las personas cercanas al transgenerismo desconfían de la voluntad de normalización de algunos/as transexuales. Consideran poco menos que una utopía el que una persona pueda ubicarse de forma normalizada en la estructura de género tras someterse al proceso de modificación corporal. Advierten además de que el deseo de invisibilizarse entre los hombres y mujeres "naturales" conlleva unas expectativas que difícilmente podrán colmarse, por lo que estas personas serán para siempre "unas atormentadas que se derrumbarán cada vez que alguien las descubra" (Gema). En lugar de vivir constantemente con el miedo al rechazo social, algunas personas transgeneristas prefieren no renegar de la propia condición personal:

Las que quieren integrarse son las que tienen más complejos. Reivindican la normalidad pero tienen tal complejo de asumir su condición que no me parecen normales. En cambio, las que no están integradas (...) lo viven con más naturalidad, menos carga autoflageladora. Y las que quieren esconder su condición trans lo tienen jodido porque hoy en día los tíos no son tontos y tarde o temprano se darán cuenta, porque la operación no cuela (Mónica).

Las muestras de hostilidad hacia el otro paradigma son más frecuentes entre las personas transexuales que entre las transgeneristas. Sin embargo, algunos de nuestros informantes nos han advertido que en algunos sectores del movimiento transgenerista se ha instalado lo que el artista intersex Del LaGrace Volcano denomina "queernormatividad", a saber, un "imperativo transgresor que crea nuevas jerarquías dependiendo de si eres más o menos queer o más o menos fluido" (en Soley-Beltrán 
2012: 92). Así pues, la vigilancia de autenticidad se produce, en mayor o menor medida, en los dos polos del espectro trans: algunos de los que persiguen la integración reprenden a aquellos que ni siguen el tratamiento hegemónico ni quieren ajustarse a los estándares de género; algunos de los que están comprometidos con el activismo crítico observan con cierto desdén, altanería o ironía los esfuerzos de aquellos que tratan de normalizarse:

Algunas dicen eso de "Si me tocan ahí delante ya dejan de ser hombres" y la verdad es que pienso que es una aberración (...) En realidad son personas jurásicas con mentalidad heteronormativa y llenas de prejuicios y estigmas (...) Hay algunas que compran salvaslips en el supermercado para que no sospechen que son hombres (...) y viven una vida de mujer que en el fondo es un postizo (...) Estas transexuales tienen tantos complejos... ise oyen sus cadenas cuando andan! (Clara).

\section{REFLEXIONES FINALES. LO TRANS, ENTRE LA NORMALIZACIÓN Y LA TRANSGRESIÓN}

Acabamos de analizar los dos grandes paradigmas de lo trans. En torno a la transexualidad encontramos a personas que quieren seguir todas las fases del proceso de modificación corporal porque desean obtener una apariencia estereotípica, esperando conseguir con ello una posición codificada dentro de nuestro sistema de sexo/ género. En cambio, alrededor del transgenerismo situamos a personas que rechazan el camino marcado por la clase médica. Son personas que no se sienten representadas por las categorías identitarias disponibles y reivindican espacios de género alternativos al binomio hombre/mujer. Es importante recordar que la transexualidad y el transgenerismo han sido concebidos como tipos ideales. Esta herramienta nos ha permitido construir abstracciones coherentes y homogéneas con fines analíticos. Aún así, no podemos olvidar que la realidad trans es mucho más diversa y compleja de lo que los tipos ideales permiten suponer.

Hemos visto asimismo las fricciones existentes entre ambos paradigmas, así como sus limitaciones, hecho que demuestra la fortaleza y capacidad punitiva del sistema de sexo/género. Las personas cercanas a la transexualidad aspiran a invisibilizarse, es decir, "pasar por" un hombre o una mujer "normales y naturales". En su proyecto de integración social reprenden a aquellas personas que visibilizan el hecho trans y no se ajustan a la imagen de discreción y moderación considerada como deseable. Sin embargo, la invisibilidad total y permanente es algo difícilmente lograble puesto que estas personas no podrán borrar del todo los rastros que delatan que están representando un género distinto al de asignación. Por su parte, en algunos sectores del movimiento transgenerista se han establecido jerarquías en función del nivel de transgresión de los códigos normativos. Aunque algunas de estas personas sienten las dificultades de encarnar cotidianamente la disidencia sexogenérica. Los cuerpos y subjetividades transgeneristas se encuentran en una situación de "invisibilidad estructural" (Turner 2008), por lo que no son reconocidos socialmente. Es precisamente la

\footnotetext{
${ }^{9}$ Clara se está refiriendo a aquellas mujeres trans que dudan de la virilidad de un hombre cuando éste les toca el pene durante una relación sexual. Este posicionamiento ha podido corroborarse a lo largo del trabajo de campo.
} 
necesidad de visibilizarse, de ser reconocibles en la interacción social, lo que hace que algunas de estas personas recurran a prácticas consideradas normalizantes - como la hormonación- en contra de sus ideales.

Como hemos constatado a lo largo del artículo, el abordaje de la transexualidad y el transgenerismo desde una óptica social - y no biomédica- conlleva interrogarse acerca de la capacidad normalizadora o transgresora de ambos paradigmas en relación al sistema de sexo/género. Si nos sumergimos en este debate, hemos de tener en cuenta que muchas de estas personas llevan a cabo sus proyectos de (re)construcción identitaria y corporal sin plantearse en ningún momento si están siendo normativas o subversivas. Por lo que esta valoración la suele efectuar una persona externa con intereses políticos y/o académicos. En este sentido, Vartabedian (2012: 354) apunta que resulta "problemático introducir reivindicaciones en colectivos que ni siquiera reconocen el significado de aquello que deberían estar reclamando". Y es que conferir un sentido político a discursos y prácticas cotidianas constituye, en cierto sentido, una usurpación del significado que, cuando menos, debe ser admitida.

El feminismo de corte esencialista ha vertido severas críticas contra las mujeres transexuales por considerar que reproducen los clásicos y opresivos estereotipos de la feminidad. Uno de los máximos exponentes de este posicionamiento es el controvertido libro de Janice Raymond, The Transsexual Empire (1994), en el que la transexualidad femenina es presentada como una suerte de caballo de Troya del androcentrismo que se infiltra en las luchas feministas para neutralizarlas. Esta actitud hostil podemos también encontrarla en algunos sectores del movimiento gay, que han mirado con desprecio a la mujer transexual por considerarla como "un tipo especial de "reina del armario" que intercambia los roles de género para eludir la etiqueta de homosexual" (King 1998: 152). Ante estas críticas, estamos de acuerdo con Riddell (2006) cuando afirma que no hay que buscar un chivo expiatorio - que siempre es el eslabón más débil de la cadena- para canalizar todo el resentimiento que produce la desigualdad y violencia del sistema. Es injusto señalar con el dedo acusador precisamente a aquellas personas que más han experimentado los mecanismos punitivos por no ajustarse a los imperativos sexogenéricos.

En cuanto al poder subversivo del transgenerismo, se puede objetar que nuestro sistema de sexo/género convierte a estas personas en "seres abyectos", es decir, son personas que no se ajustan a las categorías de género reconocidas socialmente y que, por tanto, no tienen una existencia legítima: "Lo abyecto designa (...) aquellas zonas "invisibles", "inhabitables" de la vida social que, sin embargo, están densamente pobladas por quienes no gozan de la jerarquía de los sujetos, pero cuya condición de vivir bajo el signo de lo "invivible" es necesaria para circunscribir la esfera de los sujetos" (Butler 2002: 19-20). En consecuencia, se hace difícil que estas personas puedan subvertir el sistema de sexo/género desde este espacio de rechazo o exclusión ${ }^{10}$. Dicho de otro modo: "La percepción social de los transexuales como "bichos raros" neutraliza su potencial desestabilización de las categorías de la matriz" (Soley-Beltran 2009: 409).

\footnotetext{
${ }^{10}$ Seguramente, aquí Butler diría que es difícil pero no imposible. La pensadora norteamericana considera que lo abyecto — esto es, lo rechazado, lo ininteligible - no constituye un exterior absoluto, por lo que tiene la capacidad para irrumpir y subvertir las categorías hegemónicas (Burgos 2006).
} 
El que una persona rechace el género asignado al nacer podría ser visto como una muestra más de la diversidad inherente al ser humano, o como un cuestionamiento saludable de las normas que rigen nuestro sistema de sexo/género. No obstante, la patologización y posterior medicalización actúan como un "tranquilizante social" (Raymond; en Nieto 2008: 144), pues con ellas se individualiza la insatisfacción de género en lugar de politizarse. Para la biomedicina, lo trans constituye una disfunción que tan solo atañe a la salud de la persona y a los profesionales que aplican las tecnologías necesarias para darle el cuerpo que la naturaleza le negó. Parece como si la modificación del género de asignación solo fuese posible bajo la forma de un «acto terapéutico" (Hérault 2010: 4). Este paradigma predomina tanto en los medios de comunicación como en el ámbito médico, desde donde se sigue reproduciendo una imagen de la persona transexual basada en el sufrimiento psicológico, el malestar corporal y el deseo de pasar por el quirófano. Pero la realidad trans no es uniforme sino diversa, hecho que a menudo ignoran las UTIG con protocolos excluyentes y tratamientos excesivamente estandarizados.

Ante el biologicismo patologizante y homogeneizante del paradigma biomédico, resulta indispensable que se siga abordando lo trans en clave social. Solo así estaremos en las mejores condiciones para entender que no se trata de una desviación o de un mero error, sino simplemente de diversidad. Solo así comprenderemos que el verdadero problema no es la transexualidad en sí misma, sino la transfobia social. Solo así tendremos la oportunidad de cuestionarnos las normas que nos constituyen en tanto sujetos generizados; la oportunidad para que afloren sin escandalizarnos todos esos cuerpos, deseos, actos y experiencias que escapan a la lógica hegemónica.

\section{BIBLIOGRAFÍA CITADA}

Benjamin, Harry. 1966. The Transsexual Phenomenon. Nueva York: Warner Books.

Billings, Dwight y Thomas Urban. 1998. "La construcción socio-médica de la transexualidad: interpretación y crítica", en José Antonio Nieto (comp.), Transexualidad, transgenerismo y cultura: 91-116. Madrid: Talasa.

Bolin, Anne. 1988. In Search of Eve: Transsexual Rites of Passage. Nueva York: Bergin \& Carvey.

Bourdieu, Pierre. 2003. La dominación masculina. Barcelona: Anagrama.

Burgos, Elvira. 2006. "Cuerpos que hablan", en Jorge V. Arregui y Juan A. García González (eds.), Significados corporales: 93-109. Málaga: Contrastes. Colección Monografía 11.

Butler, Judith. 2002. Cuerpos que importan. Sobre los limites materiales y discursivos del sexo. Buenos Aires: Paidós.

Butler, Judith. 2007. El género en disputa. El feminismo y la subversión de la identidad. Barcelona: Paidós.

Cabral, Mauro. (ed.) 2009. Interdicciones. Escrituras de la intersexualidad en castellano. Córdoba: Anarrés Editorial.

Coll-Planas, Gerard. 2010a. "La policía del género", en Miquel Missé y Gerard Coll-Planas (eds.). El género desordenado. Críticas en torno a la patologización de la transexualidad: 55-66. Madrid: Egales.

Coll-Planas, Gerard. 2010b. La voluntad y el deseo. La construcción social del género y la sexualidad: el caso de lesbianas, gays y trans. Madrid: Egales.

Derrida, Jacques. 1972. Positions. Paris: Les Éditions de Minuit.

Douglas, Mary. 2007. Pureza y peligro. Un análisis de los conceptos de contaminación y tabú. Buenos Aires: Nueva Visión. 
Elias, Norbert. 1990. La sociedad y los individuos. Barcelona: Edicions 62.

Fausto-Sterling, Anne. 2006. Cuerpos sexuados. Barcelona: Melusina.

Feinberg, Leslie. 2006. "Transgender Liberation: A Movement Whose Time Has Come", en Susan Stryker y Stephen Whittle (eds.). The Transgender Studies Reader. 205-220. Nueva York: Routledge.

Fisk, Norman. 1974. "Gender Dysphoria Syndrome. The Conceptualization that Liberalizes Indications for Total Gender Reorientation and Implies a Broadly Based MultiDimensional Rehabilitative Regimen". Western Journal of Medicine, 120 (5): 386-391.

Garfinkel, Harold. 2006. "El tránsito y la gestión del logro de estatus sexual en una persona intersexuada", en H. Garfinkel, Estudios en Etnometodología: 135-210. Barcelona: Anthropos.

Goffman, Erwing. 2006. Estigma. La identidad deteriorada. Madrid: Amorrortu.

Gómez-Gil, Esther; Isabel Esteva de Antonio. y Jesús A. Fernández-Tresguerres, J. 2006. "Causas o fundamentos fisiológicos", en E. Gómez-Gil e I. Esteva de Antonio (eds.), Ser transexual. Dirigido al paciente, a su familia, y al entorno sanitario, judicial y social: 113-124. Barcelona: Glosa.

Guasch, Oscar. 2005. "Género y sexualidad. Una perspectiva social y política". Archipiélago 67: $23-32$.

Guasch, Oscar. 2013. "La construcción cultural de la homosexualidad masculina en España (19701995)", en Rafael Mérida Jiménez (ed.), Minorías sexuales en España (1970-1995). Textos y representaciones: 11-25. Barcelona: Icaria.

Hausman, Bernice.1995. Changing Sex. Transsexualism, Technology and the Idea of Gender. Durham: Duke University Press.

Hausman, Bernice.1998. "En busca de la subjetividad: transexualidad, medicina y tecnologías de género", en José Antonio Nieto (comp.) (1998), Transexualidad, transgenerismo y cultura: 193-227. Madrid: Talasa.

Hérault, Laurence. 2005. "Le rite de passage et l'expérience de changement de sexe. Van Gennep en terre transsexuelle». Hermès, 43: 169-177.

Hérault, Laurence. 2010. "La métamorphose transsexuelle comme renaissance". Actes du colloque "Le corps et la loi. Du début à la fin de la vie». Aix-Marseille 3. Consulta 13 de marzo de 2015. http:/ /www.academia.edu/5543837/La_m\%C3\%A9tamorphose_transsexuelle_comme renaissance

Hobsbawm, Eric. 1994. "Identidad”. Revista Internacional de Filosofía Política, 3: 5-17.

Kessler, Suzanne y Wendy McKenna. 1985. Gender. An ethnomethodological approach. Chicago y Londres: The University of Chicago Press.

King, David. 1998. "Confusiones de género: concepciones psiquiátricas y psicológicas sobre el travestismo y la transexualidad", en J.A. Nieto (comp.), Transexualidad, transgenerismo y cultura: 123-156. Madrid: Talasa.

Kruijver, Frank; Jiang-Ning Zhou, Cris Pool, Michael Hofman, Louis Gooren y Dick F. Swaab. 2000. "Male-to-Female transsexuals have female neuron numbers in a limbic nucleus". The Journal of Clinical Endocrinology \& Metabolism, 85: 2034-2041.

Laqueur, Thomas. 1994. La construcción del sexo. Cuerpo y género desde los griegos hasta Freud. Madrid: Ediciones Cátedra, Universitat de València e Instituto de la Mujer.

Mas Grau, Jordi. 2013. "La patologización de la transexualidad. Un mecanismo legitimador de nuestro sistema dual de género". Quaderns de l'Institut Català d'Antropologia, 18(1): 65-79.

Mas Grau, Jordi. 2014. "Subjetividades y cuerpos gestionados. Un estudio sobre la patologización y medicalización del transgénero". Tesis doctoral, Universitat de Barcelona. Consulta 16 de marzo de 2015. http://www.tdx.cat/handle/10803/286741

Mas Grau, Jordi y Óscar Guasch. 2013. "El proceso de transformación corporal de personas transexuales. ¿Un camino hacia la normalización genérica?”. Revista de estudios de antropología sexual, 4 (1): 136-151.

Mira, Alberto. 2004. De Sodoma a Chueca. Una historia cultural de la bomosexualidad en España del siglo $X X$. Madrid: Egales.

Missé, Miquel y Gerard Coll-Planas. (eds.) 2010. El género desordenado. Críticas en torno a la patologización de la transexualidad. Madrid: Egales.

Money, John y Anke Ehrhardt. 1982. Desarrollo de la sexualidad humana. Diferenciación y dimorfismo de la identidad de género. Madrid: Ediciones Morata.

Nieto, José Antonio. 2008. Transexualidad, intersexualidad y dualidad de género. Barcelona: Edicions Bellaterra. 
Prince, Virginia. 1997. "Seventy Years in the Trenches of the Gender Wars", en Bonnie Bullough, Vern Bullough y James Elias (eds.), Gender Blending: 469-476. Nueva York: Prometheus Books.

Raymond, Janice. 1994. The Transsexual Empire. The Making of the She-Male. Nueva York: Athene Series.

Riddell, Carol. 2006. "Divided Sisterhood. A Critical Review of Janice Raymond's The Transsexual Empire", en Susan Stryker y Stephen Whittle (eds.), The Transgender Studies Reader: 144-158. Nueva York: Routledge.

Rubin, Gayle. 1986. "El tráfico de mujeres: notas sobre la "economía política" del sexo". Nueva Antropología 30(8): 95-145.

Soley-Beltran, Patricia. 2009. Transexualidad y la matriz heterosexual. Un estudio crítico de Judith Butler. Barcelona: Edicions Bellaterra.

Soley-Beltran, Patricia. 2012. "No-body is perfect". Transexualidad y performatividad de género", en Patricia Soley-Beltran y Leticia Sabsay (eds.), Judith Butler en disputa. Lecturas sobre la performatividad: 59-100. Madrid: Egales.

Stoller, Roberto. 1968. Sex and Gender. Vol.I. The Development of Masculinity and Femininity. Nueva York: Science House.

Stoller, Roberto. 1975. Sex and Gender. Vol. II. The Transsexual Experiment. Londres: The Hogarth Press/The Institute of Psycho-Analysis.

Stryker, Susan. 2006. "(De)Subjugated Knowledges. An Introduction to Transgender Studies", en Susan Stryker y Stepeh Whittle (eds.), The Transgender Studies Reader. 1-18. Nueva York: Routledge.

Stryker, Susan y Aren Aizura. (eds.) 2013. The Transgender Studies Reader 2. Nueva York: Routledge.

Stryker, Susan y Stephen Whittle. (eds.) 2006. The Transgender Studies Reader. Nueva York: Routledge.

Turner, Victor. 2008. La selva de los simbolos. Madrid: Siglo XXI.

Van Gennep, Arnold. 1986. Los ritos de paso. Madrid: Taurus.

Vartabedian, Julieta. 2012. "Geografía travesti: cuerpos, sexualidad y migraciones de travestis brasileñas (Rio de Janeiro-Barcelona)". Tesis doctoral, Universitat de Barcelona. Consulta 19 de febrero de 2015. http://www.tdx.cat/bitstream/handle/10803/95889/JVC_TESIS.pdf?sequence=1

Zhou, Jiang-Ning, Michael Hofman, Louis Gooren y Dick Swaab, D. 1995. "A sex difference in the human brain and its relation to transsexuality". Nature 378: 68-70.

Fecha de recepción: 18 de marzo de 2015

Fecha de aprobación: 25 de junio de 2015 